Гаджилова Ш. М.

Аннотация. Цель исследования - раскрыть художественные особенности и жанровые мотивы элегии М. Ахмедова в контексте аварских художественных традиций. Особое внимание уделяется элегии М. Ахмедова как жанру, вобравшему в себя элементы философской, пейзажной, гражданской, любовной лирики. В центре внимания - художественное своеобразие стихов М. Ахмедова, написанных в жанре элегии. Научная новизна исследования заключается в том, что впервые вводятся в научный оборот элегии М. Ахмедова, рассматриваются их художественное своеобразие и жанровые мотивы в контексте соответствующей традиции аварской поэзии. Результаты исследования показали, что жанр элегии в поэзии М. Ахмедова развивается в тесной связи с другими лирическими жанрами. Элементы гражданственности, патриотичности раскрывают философское мировидение поэта в элегии, элементы пейзажной и любовной лирики усиливают художественные особенности элегий, их жанровые мотивы.

\title{
EN Artistic Features and Genre Motifs of M. Akhmedov's Elegy
}

\author{
Gadjilova S. M.
}

\begin{abstract}
The purpose of the study is to shed light on artistic features and genre motifs of M. Akhmedov's elegy in the context of the Avar artistic traditions. Special attention is paid to M. Akhmedov's elegy as a genre incorporating elements of philosophical, landscape, civil, amorous poetry. The focus of the study is artistic originality of M. Akhmedov's poems written in the genre of elegy. The research is novel in that it is the first to introduce M. Akhmedov's elegies into scientific use, to consider their artistic originality and genre motifs in the context of the corresponding tradition of the Avar poetry. The research findings have shown that the elegiac genre in M. Akhmedov's poetry develops in close connection with other lyric genres. Elements of civil, patriotic nature reveal the author's philosophical worldview in the elegy, elements of landscape and amorous poetry heighten artistic features of elegies, their genre motifs.
\end{abstract}

\section{Введение}

Актуальность заявленной темы обусловлена необходимостью объективного изучения произведений М. Ахмедова, написанных в жанре элегии, выявления развития аварских художественных традиций с элементами рассматриваемого жанра в творчестве поэта. Представленный в работе анализ элегии М. Ахмедова позволит восполнить пробел в изучении жанра элегии в творчестве поэта. Такой подход к изучению рассматриваемой проблемы, на наш взгляд, расширит исследовательское представление о поэзии М. Ахмедова. Вместе с тем привлеченный в настоящей статье материал о жанре элегии в поэзии М. Ахмедова может расширить информацию о развитии этого жанра в аварской поэзии, стать весомым вкладом в развитие современного дагестанского литературоведения.

В соответствии с целью определены следующие задачи: исследовать художественные особенности и жанровые мотивы элегии М. Ахмедова в контексте развития художественных традиций аварской элегии; проанализировать характерные элегии М. Ахмедова элементы философской, гражданской, пейзажной, любовной лирики.

В ходе работы применены следующие методы исследования: сравнительно-исторический, сравнительносопоставительный и метод целостного анализа литературного произведения.

В процессе выполнения данной работы мы в основном опирались на труды дагестанских ученых 3. 3. Гаджиевой «Аварская элегическая лирика», Ч. С. Юсуповой «Три десятилетия аварской поэзии», «Чанка. Тажудин из Батлаича. Поэзия высокой скорби и вознесений», С. М. Хайбуллаева «Поэзия высокого накала», в которых рассмотрена картина развития жанра элегии в аварской поэзии. Вместе с тем теоретической базой исследования стали сборники статей известных дагестанских критиков и писателей «Литература Дагестана и жизнь», «Жанрово-стилевые поиски советской литературы 70-х годов». 
Практическая значимость работы заключается в расширении литературоведческих подходов к изучению жанра элегии в аварской поэзии и жанровой системы дагестанской поэзии в целом. Результаты нашего исследования могут быть использованы при составлении лекционных курсов для студентов, магистрантов и аспирантов вузов и других учебных заведений, при написании курсовых и дипломных проектов по литературоведческой проблематике, а также при изучении творчества М. Ахмедова.

\section{Художественные особенности и жанровые мотивы элегии М. Ахмедова в контексте развития художественных традиций аварской элегии}

Грустное, скорбное произведение с печальным настроением или жалобное стихотворение, пронизанное красками сентиментализма, раздумьями о безответной любви, воспоминаниями о прошедшей жизни, размышлениями о смерти и быстротечности жизни - все это относится к краткой характеристике элегии как одного из лирических жанров в литературе.

В жанре элегии написаны многие произведения советских и постсоветских аварских литераторов. По мнению исследователя аварской элегической лирики 3. 3. Гаджиевой, термин «элегия» в литературы народов Дагестана вошел в послевоенные годы и имел смысловой оттенок, принятый в русской поэзии. Все же было бы несправедливо вынести заключительную мысль о генезисе и развитии аварской элегии как о следствии влияния только русской элегической книги. Здесь уместно вспомнить, что первая художественная мысль, известная как образец философской лирики основателя аварской художественной литературы Мухаммеда из Кудутли («Снег на горе»), выражена на фоне философско-элегического поля. Отсюда мы можем уверенно констатировать, что элегия имеет самое прямое отношение к истокам аварской художественной мысли вообще. Вслед за Мухаммедом из Кудутли почти вся когорта арабоязычных аварских поэтов оставила после себя довольно солидный пласт, к которому можно относить произведения «грустных раздумий» или «с печальным настроением». Примечательна, к примеру, в этом плане элегия-плач Абдулатифа Гоцинского, написанная на смерть сына Шамхала, известного наиба имама Шамиля. В ней автор искусно раскрывает свое отношение к смерти, свое видение, понимание смерти как перехода в новую жизнь, свою веру в бессмертие души. Также уместно здесь вспомнить произведение, наполненное печальным настроением и грустными раздумьями о смысле и сущности жизни, написанное в годы Кавказской войны Саидом из Аракани. Арабоязычные аварские элегии-плачи в основном посвящались памяти известных ученых или общественных деятелей. Арабоязычная литература дореволюционного периода была определенным рычагом воздействия на национальное художественное сознание дагестанцев, фактором влияния на формирование самобытной литературы. В арабоязычной дагестанской, в частности аварской, литературе жанр элегии в основном появился под влиянием арабской классической формы траурной песни - риса или марсия, имеющих родственное отношение к другому жанру под названием мадх (восхваление). И в первом, и во втором случае произведение пронизано восхвалением человека, мадх - восхвалением живого человека (справедливого правителя, верного друга, мудрого учителя и т.д.), а риса - восхвалением человека, который уже умер, и здесь восхваление покойного сопровождается плачем. Говорить об интересной теме трансформации этого жанра можно очень долго, поэтому здесь важно отметить главное - отличие дагестанской рисы от арабской заключается в том, что в дагестанском варианте рисы отсутствуют элементы пышности, чрезмерной вычурности, она почти всегда отражает реальные события и передает правдивую, невыдуманную картину характера оплакиваемого образа.

Тенденция распространения научно-философской, литературной мысли под влиянием арабо-мусульманского художественного мышления импульсивно развивалась в литературах Дагестана вплоть до начала двадцатого века. Однако с тех пор, как литературы народов Дагестана начали активно взаимодействовать с традициями русской литературы, незаметно исчезли арабские названия жанра «марсия» или «риса», фигурировавшие в литературе вплоть до начала XX века. Что касается исконно национального названия плачей «маг1о», то это уже воспринималось как фольклорный образец. Безусловно, при рассмотрении генезиса и развития элегии как жанра в аварской литературе нельзя игнорировать и народный фактор. Фольклорные образцы, которые лежат в основе художественного сознания как целого народа, так и отдельных авторов, в том числе и М. Ахмедова, прошли разные исторические периоды, в последующем к ним добавились смысловые оттенки русской элегии и арабской марсии. Так появилась аварская советская элегия, которая постоянно развивалась, расширяла диапазон своих идей, тем и проблематики.

Элегия народного поэта Дагестана М. Ахмедова представляет собой особую систему ценностей, в которой понятие «красота» выступает как один из составляющих элементов, мотивирующих поэта показать невозвратность мгновения красоты или же чувство живой грусти об ее исчезновении. Красота человека, красота жизни, красота души, красота мысли, красота любви - все это для поэта сконцентрированные во времени и пространстве элементы бытия, которые придают жизни целостность и вместе с тем могут быть или, по законам природы, должны быть утеряны. Поэт устанавливает «широкие, глубокие, крепкие связи между явлениями природы и человеческой жизни» [8, с. 134], отсюда понятие «тленное» почти всегда сопровождает понятие «вечное». Вечное и тленное в элегиях М. Ахмедова, как и в его философских стихах, становятся жанрообразующей осью, вокруг которой рождаются смешанные эмоции поэта. Если в предыдущие, в частности дореволюционные, этапы (Чанка, Анхил Марин, Эльдарилав, Магомед из Чиркея и др.) аварская «элегия была предназначена для скорбного пения над умершими» [10, с. 366], то в поэзии М. Ахмедова список элегических произведений 
всегда может быть скорректирован или же дополнен. Более того, нужно здесь учитывать и тот факт, что в творчестве М. Ахмедова встречаются произведения, находящиеся на границе, на стыке двух жанров, такие как элегиябаллада, поэма-баллада и т.д. Так, значительное число его произведений выполнено в элегическом модусе.

Элегии М. Ахмедова характерны непостоянство, изменчивость, трансформация с одного фона на другой, отсутствие однозначности чувства поэта, она охватывает все думы, настроения и душевные поиски поэта. Такая тенденция развития внутренней художественной структуры этого жанра также характерна для творчества О.-Г. Шахтаманова, Р. Гамзатова, Ф. Алиевой и других представителей советского и современного периодов аварской поэзии. «Этот процесс объясняется стремлением художников слова всеми доступными им средствами изображать действительность во всей глубине и широте, пробовать свои силы в нетрадиционных для их национальной культуры жанрах, обогащать свою творческую лабораторию» [9, с. 94]. Особое значение здесь имеет психологизм как основное художественное средство, вызванное стремлением раскрыть внутренний мир поэта, человека. Так, М. Ахмедов часто прибегает к психологизму с характерной для него энергетикой литературного духа. Здесь уместно вспомнить высказывание В. Э. Вацуро, характеризующее признаки элегии и подтверждающее теорию о «смешанных эмоциях», которая играет доминирующую роль в жанрообразующей структуре элегии. Вот что он пишет: «Душа, захваченная страстью или подавленная страданием, либо вовсе не способна к самовыражению, либо изливает себя в одическом лиризме и в бурной элегии трагического монолога, но когда она выходит из этого состояния, в ней пробуждаются исконно присущие ей противоположные ощущения, смягчающие и умеряющие страдание. Возникает психологическая ситуация элегии» $[4$, с. 127]. Рассмотрим это на примере элегии М. Ахмедова.

Хасел. Элегия... Хинлъи лъугІараб

ГІагараб гъасда дун дунго хутІана.

Гьороца нуцІида цІумур бан буго,

ЦІороялъ гордазда кІутІулеб буго.

Дун тІаде вахъана, нуцІа рагьана,

Рагьдухъ эхетун чІун рагІад батана.

РагІана хъудулеб гІазул музыка...

РагІад гІадан гІадин аскІобе щвана.

Дун нахъегІан къана... ЖанахІалъубе, ЖужахІалъул кьерлъун рагІад лъугьана.

ЛъугІулареб бецІлъи... Балагьал берал,

Гьале дун чІвазелъун ралагьун чІана:

ЧІвана дун гІумруялъ, чІвана гІадамаз;

ЧІвана рокьукълъиялъ, чІвана йокьулелъ.

ЧІвана гьудулзабаз, чІвана тушбабаз,

ЧІвана дун лъикІлъиялъ, чІвана квешлъиялъ.

Хасел. Элегия... Хинлъи лъугІараб

Хирияб гъасда дир канлъи лъуг1ана [3, с. 487]. /

Осень. Элегия... Пропало тепло,

У родного очага один я остался.

Ветер повесил колокольчик на двери,

Холод стучится в окно.

Я встал, дверь открыл,

На улице тень нашел стоящую.

Шум музыки снега я слышу,

Тень, словно человек, подходит ко мне.

Я отошел назад... в комнату,

Тень теперь словно цвет ада,

Бесконечная темнота, глаза беды

Смотрят на меня, чтобы убить меня:

Убила меня жизнь, убили люди;

Убила ненависть, убила любимая.

Убили друзья, убили враги,

Убила доброта, убило меня зло.

Осень. Элегия... пропало тепло,

У очага родного потерял я свет

(здесь и далее перевод автора статьи. - Ш. Г.).

Как видно, элегия М. Ахмедова является глубоко личным произведением поэта. Она напоминает философские максимы и сопровождается эпическими выводами, которые выражены в форме личных, душевных переживаний. 
«Движение лирического сюжета во всей элегии и в каждой ее части поддерживается естественными переливами чувств, внезапностью выходов сложной совокупности медитативной энергии. Элегическую озвученность интонации придает смысловой потенциал используемых лексем» [5, с. 99]. Краска меланхолии и пессимизма закрепляет цвет элегической стихии душевных волнений поэта, передающихся через различные стилистические и образные средства. Основная ситуация элегии М. Ахмедова - это несчастная любовь, одиночество поэта. Рамки грустных рассуждений поэта вбирают в себя такие разновидности художественных тем, как «вечерняя элегия», элегия «на смерть поэта», «унылая» элегия, элегия воспоминаний, «осенняя» элегия, «весенняя» элегия и другие. В каждой из выделенных моделей вырисовывается свое лирическое «Я», авторская логика, имеющая связь с историко-литературным происхождением и развитием жанра элегии в аварской поэзии.

Погруженность лирического героя в себя, обращение к своим эмоциям, переживаниям, мотив разочарования, мотив жизненных бурь, полного забвения, мотив разрушительного хода времени - все это в элегии М. Ахмедова становится элементами обновления или обогащения элегии как литературного жанра. Мотив сопротивляющейся, но уступающей и угасающей эмоции красной нитью проходит и в представленной выше элегии, в которой раскрывается плачевная картина современного мира сегодняшнего дня.

Условно можно сказать, что история элегии как жанра - это история лирической поэзии вообще, отражающая голос времени, в котором жил и творил тот или иной представитель художественного творчества. Так, в элегии М. Ахмедова элементы философской, гражданской, пейзажной, любовной лирики усиливают голос времени или краски картины современного мира.

\section{Элементы философской, гражданской, пейзажной, любовной лирики в элегии М. Ахмедова}

Элегия в поэзии М. Ахмедова формируется как смешанный жанр, которому характерны элементы философской, пейзажной, гражданской, любовной лирики. Поэт как бы прощупывает сложную гамму жизненных проекций, где основной линией выделяется неудержимая жажда человека и человечества к жизни. Констатация сложного течения жизни, ее противоречивости, суетности и бренности, незащищенности человека придает поискам поэта философско-рационалистический характер.

Во всех ситуациях в основе жанровой модели обнаруживается определенная конфигурация художественного мира лирического «я» или лирического субъекта. В той или иной лирической ситуации, перерастающей в лирический сюжет, лирическое «я» всегда остается в печали или разочаровании, но не всегда состояние поэта выражает мотив меланхолии или пессимизма. К примеру, в элегии, посвященной памяти Н. Рубцова, М. Ахмедов красочно рисует картину осеннего «сентябрьского сада», с которым ассоциируется в воображении поэта всеобщая печаль, грусть, «унылая» осенняя пора здесь ассоциируется со смертью поэта. Осень как источник знания о жизни и ее закономерностях дает читателю урок умирания, который привносит в жанр способность видеть сюжет жизни человека в мире. Отсюда драма осенней элегии вбирает в себя общечеловеческий масштаб.

Сентябралъул ахикь

Холеб буго сихІкъотІи,

Къваридал гъутІби руго

Гъаримго гаргадулел.

Меседил рахсалги ран

Рухьун рушел кинигин,

Киназулго пашманлъи

Цолъун бихьулеб буго [2, с. 135]. /

В саду сентября

Умирает тишина,

Грустные деревья

Тихо беседуют.

Золотыми цепями

Будто связаны они,

Печаль каждого

Видно, что стала общей она.

Далее поэт рисует образный портрет беды, которая «смотрит на него сквозь золотые деревья» так, чтобы этого не заметил никто, она целится в сердце поэта, «счастье предает» поэта, «радость хранит молчание», «журавли печали» постоянно плачут. Здесь вспоминает поэт о «днях, прожитых зря», и о «мечтах, оставленных в тюрьмах своих дней», далее срывается лирический сюжет, и вдруг пессимизму на смену приходит оптимистическая нота.

Дица дуда гьарила,

Гьудул тІаса лъугьайин.

Дуца дида гьарила,

Гьудул тІаса лъугьайин... 
РекІелъ бук1араб бакІлъи

ЛъугІун ина лахІзаталъ,

Пашманлъидул къункърабаз

АхІила рохалил кечI [Там же, с. 136]. /

Я попрошу тебя:

Прости меня, друг.

Ты попросишь меня:

Прости меня, друг.

Тяжесть, что в сердце была,

Вдруг исчезнет, пропадет,

И журавли печали

Песню радости споют.

В элегиях М. Ахмедова иногда смыслообразующую роль играет мотив ухода в молчание, который сопровождается поисками идеала или навязчивыми воспоминаниями, что придает художественной мысли автора некую метафизичность, главное лирическое событие здесь - откровение высшей гармонии или сюжет упоения, выступающий как ядро символизма.

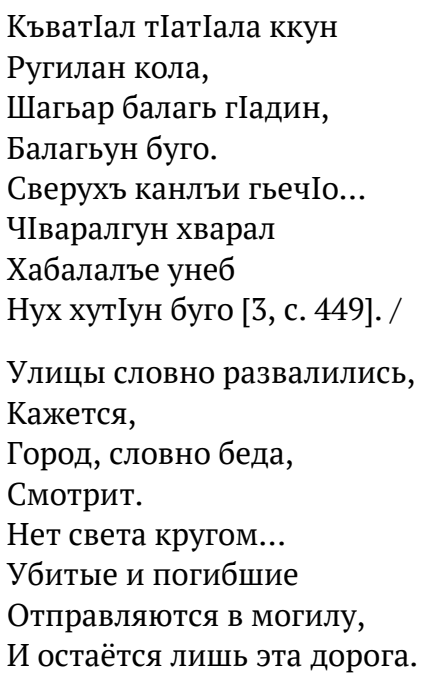

«Чувство, вызывающее на раздумье, требующее углубленной сосредоточенности при анализе сердечных движений, - примета, всегда сближавшая элегическую лирику с философской. Это придает также и драматизм сокровенным порывам, открывает дополнительные оттенки в теме Родины, поддерживает и усиливает элегическое состояние души, обогащает интеллектуальные поиски» [7, с. 126]. Так это представляется в данном случае:

Огь гІагараб ВатІан,

РитІухълъиялъул

РетІел тІу-тІун буго,

ТІупан тІун буго [3, с. 449]. /

Ах, Родина родная,

Справедливости

Одежда порвана,

Обрушился ливень.

Или:

Къоабилеб векалъ

Канлъи босарал

Берал нагІанадул

МагІил цІун руго [Там же, с. 450]. /

Двадцатый век

Лишил зрения,

И глаза наполнены

Слезами проклятия.

С самой первой строфы в одном коротком обращении к родине создается атмосфера патриотичности, гражданственности. Далее разворачивается описание картины времени, причем посредством символов. Слово «справедливость» раскрывается как абстрактная ценностная категория, которая в данном тексте интерпретируется через метафору («одежда справедливости»). Предметная метафора (предмет-объект) рассчитана 
здесь на видение различных смыслов, аспектов ситуации и самого феномена справедливости. Метафора пространства и движения в представленном выше отрывке «двадцатый век зрения лишил» далее реализуется как исключительно фоновое осмысление предыдущего пункта - «утеря справедливости». Элементы социальной и философской проблематики, о которых мы упомянули выше, можно сказать, целиком и полностью раскрываются именно метафорами, которые присутствуют во всём тексте.

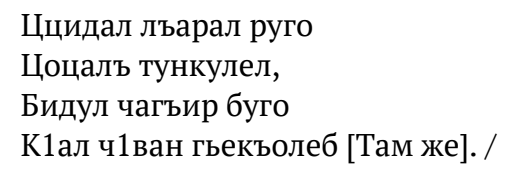

Реки ненависти

Толкаются друг с другом,

Вино крови

Пьют (страстно) устами.

Метафора была охарактеризована еще Аристотелем таким образом: «...переносное слово (метафора) - это несвойственное имя, перенесенное с рода на вид, с вида на род, или с вида на вид, или по аналогии» [1, с. 158].

Здесь метафора выступает как языковое выражение, вобравшее в себя всю смысловую нагрузку строфы. Задача метафоры М. Ахмедова в данном случае, впрочем, как и всегда, - раскрыть как буквальное, так и переносное значение художественной мысли поэта. Резюмируя значение своих высказываний, М. Ахмедов завершает свой элегический монолог следующим образом:

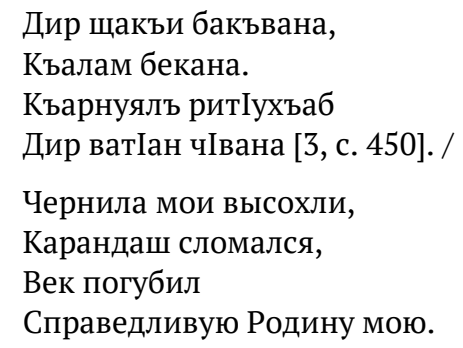

Как видно, тема патриотизма, тема скорбных размышлений о страданиях народа и взгляд поэта на современную действительность в полной мере раскрыты через философское видение поэта. В нем - «страстная любовь поэта к Отчизне и самая сильная ненависть, безжалостное осуждение тех, кто однажды предал его» [6, с. 373]. Центральное место в произведениях М. Ахмедова, написанных в жанре элегии, занимают критическое отношение поэта к действительности, «противопоставление ей своего идеала жизни, утверждая таким образом внутреннюю независимость человеческой личности, не желающей примириться с бездуховностью и произволом современного общества» [12, с. 189].

\section{Заключение}

Таким образом, в ходе анализа произведений М. Ахмедова, написанных в жанре элегии, мы пришли к следующим выводам. Развитие элегии как жанра - это процесс ее непрерывного движения к сближению, а иногда даже и смешивания с другими, близкими к себе лирическими жанрами. Этот процесс - не единичный случай в поэзии М. Ахмедова, он характеризует объективные предпосылки динамики развития жанровой системы аварской литературы в целом. К нарушению установленных еще в дореволюционной литературе канонов, к утрате специфики элегии, а порою даже к своеобразному её «перевоплощению» в поэзии М. Ахмедова привели, на наш взгляд, межлитературные связи, опыт преемственности и заимствования, характерные не только аварскому, но и вообще мировому литературному процессу. Отсюда можно объяснить философское мировидение в элегии М. Ахмедова, наличие в ней атмосферы гражданственности, патриотичности. Элементы пейзажной и любовной лирики позволяют М. Ахмедову создать подходящие мотивы для усиления трагизма, грусти, печали, что является немаловажной особенностью элегии как жанра. «Они вызывают у читателя чрезвычайно сильные позитивные и негативные эмоции, чувства печали и счастья, слезы и радость, надежды и разочарования, создающие в поэтическом сочетании и равновесии, по существу, новую художественную эмоцию и философский идеал соразмерностей» [11, с. 273].

Перспективы дальнейшего исследования видятся во всестороннем изучении поэзии М. Ахмедова, что будет способствовать целостному осмыслению его поэтического мировидения и миропонимания, а также его художественного метода, который может быть изучен на фоне развития аварской современной поэзии.

\section{Список источников}

1. Аристотель. Поэтика // Аристотель. Сочинения: в 4-х т. М.: Мысль, 1983. Т. 4. С. 376-600.

2. Ахмедов М. Годы. Махачкала: Дагестан. кн. изд-во, 1993. 397 с. 
3. Ахмедов М. Поэт и родина. Махачкала: Дагестан. кн. изд-во, 2006. 806 с.

4. Вацуро В. Э. Лирика пушкинской поры. «Элегическая школа». СПб.: Наука, 1994. 241 с.

5. Гаджиева 3. З. Аварская элегическая лирика. Махачкала: Ред. изд. предприятие Госкомпечати РД, 1997. 150 с.

6. Гаджилова Ш. М. Творчество М. Ахмедова в контексте патриотических традиций аварской поэзии // Филологические науки. Вопросы теории и практики. 2020. Т. 13. Вып. 12. С. 369-374.

7. Глинкин П. Е. Поиск - Позиции - Жанр // Жанрово-стилевые поиски советской литературы 70-х годов: межвуз. сб. / отв. ред. Е. А. Никулина. Л.: Изд-во Ленингр. ун-та, 1981. С. 120-133.

8. Хайбуллаев С. М. Поэзия высокого накала. Махачкала: Дагкнигоиздат, 1990. 152 с.

9. Хайбуллаев С. М. Современная дагестанская поэзия. Махачкала: Дагучпедгиз, 1996. 164 с.

10. Шеллинг Ф. В. Философия искусства / пер. с нем. П. С. Попова. М.: Мысль, 1966. 496 с.

11. Юсупова Ч. С. Расул Гамзатов в расколотом мире (1985-2000). Махачкала: ГУП Тип. ДНЦ РАН, 2007. 381 с.

12. Юсупова Ч. С. Чанка. Тажудин из Батлаича. Поэзия высокой скорби и вознесений. Махачкала: Ин-т ЯлИ ДНЦ PAH, 2012. 200 c.

\section{Информация об авторах | Author information}

RU Гаджилова Шанисат Магомедовна ${ }^{1}$, к. филол. н.

${ }^{1}$ Институт языка, литературы и искусства имени Г. Цадасы

Дагестанского федерального исследовательского центра Российской академии наук, г. Махачкала

EN Gadjilova Shanisat Magomedovna ${ }^{1}, \mathrm{PhD}$

${ }^{1}$ Institute of Language, Literature and the Arts n.a. G. Cadasy, RAS, Makhachkala

${ }^{1}$ shanisat05@yandex.ru

\section{Информация о статье | About this article}

Дата поступления рукописи (received): 12.02.2021; опубликовано (published): 09.04.2021.

Ключевые слова (keywords): М. Ахмедов; элегическая лирика; жанровые мотивы; художественные особенности; аварская поэзия; M. Akhmedov; elegiac lyric; genre motifs; artistic features; Avar poetry. 